\title{
OPTIMALISASI PENGGANTIAN BAHAN IKAT SMART CONCRETE (SELF HEALING CONCRETE) UNTUK DAERAH RAWAN GEMPA
}

\author{
Rima Sri Agustin ${ }^{1}$, Stefanus Adi Kristiawan ${ }^{2}$ \\ ${ }^{1}$ Fakultas Keguruan dan Ilmu Pendidikan, Universitas Sebelas Maret Surakarta. \\ ${ }^{2}$ Fakultas Teknik, Universitas Sebelas Maret Surakarta
}

\begin{abstract}
ABSTRAK
Inovasi dalam perkembangan teknologi beton menampilkan jenis beton yang mempunyai kemampuan untuk menyembuhkan diri saat terjadi keretakan yang dikenal sebagai self healing concrete (SHC). Rancang campur SHC mencakup kelecekan (workability,) kuat tekan dan permeabilitas. Penggunaan fly ash bervariasi dari $0-55 \%$ dari berat semen yang digantikan.

Pemanfaatan fly ash dalam beton berfungsi mengubah $\mathrm{CaOH}$ menjadi $\mathrm{C}-\mathrm{S}-\mathrm{H}$. $\mathrm{CaOH}$ merupakan unsur lemah dalam beton menjadi C-S-H yang memiliki fungsi pengikat dan memberikan kontribusi pada kekuatan beton. Butiran fly ash yang berukuran lebih kecil dari semen dimanfaatkan sebagai filler yang memiliki peran ganda: sebagai pengisi ruang-ruang kosong antar agregat dalam beton sehingga gradasi campuran lebih "smooth" sekaligus berperan sebagai lubrikan yang dapat meningkatkan workability campuran (Haque et al 1984). Pemakaian fly ash juga akan mengurangi penggunaan semen, makin sedikit semen yang digunakan akan menurunkan suhu reaksi sehingga kemungkinan retak akibat efek termal tereduksi (Mehta et al 2006). Pengurangan jumlah semen juga berdampak pada peningkatan workability campuran beton. Ditinjau dari permeabilitas, butiran fly ash yang halus akan meningkatkan kepadatan beton sehingga akan semakin kecil permeabilitasnya.

Dari hasil pengujian, analisis data dan pembahasan maka dapat ditarik beberapa kesimpulan sebagai berikut: Penggunaan fly ash dengan kadar tertentu dapat mempengaruhi sifat beton segar yang dihasilkan, semakin tinggi kandungan fly ash yang digunakan semakin baik pula workability dan flowability beton segar yang dihasilkan. Penggunaan material fly ash dapat menurunkan biaya produksi untuk beton normal yang memiliki sifat self healing concrete (SHC) karena dapat mereduksi sebagian atau lebih kebutuhan penggunaan semen pada campuran beton. Salah satu faktor utama yang mempengaruhi nilai kuat tekan beton adalah umur beton. Penggunaan kadar fly ash diatas 50\% dari berat binder yang digunakan memiliki nilai kuat tekan awal yang kurang baik untuk pengerjaan beton yang memerlukan waktu pengerasan dan kekuatan awal yang tinggi, karena proses pengerasan (setting time) dan penambahan kekuatan betonnya agak lambat pada umur beton kurang dari 28 hari. Setelah umur 28 hari kuat tekan beton yang menggunakan fly ash sebagai penggantian sebagian semen mengalami kenaikan sebesar $25 \%$ pada kadar $10 \%, 20 \%, 25 \%, 30 \%, 35 \%$ dan $45 \%$ dibanding dengan beton konvensional. Tetapi pada kadar 55\% kuat tekan beton menurun. Kuat tekan optimum terjadi pada kadar 45\%. Penggunaan fly ash sebagai pengganti semen dapat memperkecil nilai koefisien permeabilitas beton. Berdasarkan uraian tersebut,maka SHC diharapkan mempunyai kelebihan dibandingkan dengan beton konvensional dalam hal kelecekan (workability), kuat tekan dan permeabilitas yang akan meningkatkan ketahanan beton (durability).
\end{abstract}

Kata kunci: fly ash, self healing concrete, workability, durability, permeabilitas

\section{PENDAHULUAN \\ Latar Belakang}

Bahan bangunan yang umum dipakai untuk konstruksi bangunan sekarang ini adalah beton. Beton adalah batu buatan terbuat dari campuran adukan semen, agregat halus, agregat kasar dan air yang dibentuk sedemikian rupa sehingga menjadi struktur beton untuk bangunan. Beberapa kelebihan dari beton adalah mudah dibentuk menggunakan bekisting yang sesuai dengan kebutuhan struktur bangunan, tahan terhadap temperatur tinggi jadi aman jika terjadi kebakaran gedung, atau setidaknya masih memberikan kesempatan kepada penghuni pada saat bencana terjadi. Biaya pemeliharaan beton juga rendah, lebih murah jika dibandingkan dengan baja, mempunyai kuat tekan yang tinggi, mudah didapat bahan bakunya, karena Indonesia merupakan negara yang kaya akan sumber daya alam misalnya pasir yang dapat ditemukan di pegunungan maupun di dasar laut.

Namun dibalik kelebihan yang dimiliki oleh beton jika dibandingkan dengan bahan material lainnya, beton juga memiliki masalah yang dapat mengurangi keunggulannya. Diantara masalah yang sering dijumpai adalah masalah keretakan yang terjadi pada bahan tersebut. Keretakan pada beton dapat timbul pada saat prakonstruksi dan pasca konstruksi. Sebenarnya setiap 
beton yang diaplikasikan pada struktur bangunan pasti akan terjadi retakan, yang harus dipertimbangkan adalah apakah retakan tersebut dapat ditolerir karena tidak berbahaya atau retakan tersebut membahayakan struktur bangunan secara keseluruhan.

Keretakan beton yang terjadi pada prakonstruksi disebabkan oleh beberapa hal, antara lain pengaruh dari sifat beton itu sendiri maupun faktor lingkungan luar yang mempengaruhi beton secara langsung. Dilihat dari sifat beton sendiri, dalam proses pengerasannya beton akan mengalami pengurangan volume dari volume awal. Umumnya hal ini disebabkan air yang terkandung pada campuran beton akan mengalami penguapan sebagian yang mengurangi volume beton tersebut sehingga akan terjadi retakan. Sedangkan faktor dari luar antara lain suhu atau cuaca. Indonesia terdiri dari dua musim yaitu musim kemarau dan penghujan, hal tersebut mengakibatkan kembang susut dari beton yang akan mengakibatkan keretakan pada beton.

$$
\text { Keretakan }
$$$$
\text { beton }
$$

pasca

konstruksidisebabkan adanya beban dari luar yang harus ditahan oleh konstruksi beton (balok, kolom dan pelat) seperti adanya gempa, mengingat Indonesia merupakan daerah rawan gempa.

\section{Tujuan Penelitian}

Penelitian ini dilakukan dengan tujuan khusus untuk membuat rancang campur beton pintar (smart concrete) yang mempunyai kemampuan untuk menyembuhkan diri saat terjadi keretakan (self healing concretel SHC) pada keretakan pra-konstruksi. SHC dibuat dengan memanfaatkan fly ash sebagai pengganti bahan ikat. Penggantian ini diyakini dapat menambah kelecekan (workability) dari campuran beton karena fly ash mempunyai sifat memperlambat proses hidrasi. Selain itu, sifat mekanik seperti kuat tekan dan modulus elastisitas masuk kategori beton struktural (kuat tekan lebih dari $20 \mathrm{Mpa}$ ) bahkan berpotensi masuk kategori beton mutu tinggi. Penggunaan fly ash bervariasi dari $0-55 \%$ dari berat semen yang digantikan.

\section{METODOLOGI PENELITIAN \\ Benda Uji}

Dalam penelitian ini variabel-variabel yang di teliti meliputi :

1. Variabel bebas
Variabel bebas dalam penelitian ini adalah kadar fly ash yang di tambahkan dalam campuran, sedangkan variabel terikat dalam penelitian ini adalah kelecekan, kuat tekan dan Permeabilitas. Variasi jumlah fly ash sebagai pengganti semen sebesar $0 \%, 10 \%, 20 \%, 25 \%$, $30 \%, 35 \%, 45 \%$ dan $55 \%$ dari berat semen dan diuji pada usia 7 hari, 28 hari dan 56 hari. Masing-masing variasi dibuat 3 benda uji, untuk lebih jelasnya dapat dilihat pada Tabel 1.

2. Variabel terikat

Variabel terikat dalam penelitian ini meliputi kelecekan, kuat tekan dan permeabilitas.

Tabel 1. Rencana benda uji

\begin{tabular}{|c|c|c|c|c|c|}
\hline \multirow[b]{2}{*}{ No. } & \multirow[b]{2}{*}{ Kode } & \multirow[b]{2}{*}{$\begin{array}{c}\text { Jumlah } \\
\text { fly ash } \\
(\% \\
\text { berat } \\
\text { semen) }\end{array}$} & \multirow[b]{2}{*}{$\begin{array}{l}\text { Umur } \\
\text { beton }\end{array}$} & \multicolumn{2}{|c|}{ Jenis Pengujian } \\
\hline & & & & $\begin{array}{c}\text { Kuat } \\
\text { tekan } \\
\text { (silind } \\
\text { er) }\end{array}$ & $\begin{array}{l}\text { Permeabilit } \\
\text { as } \\
\text { (silinder) }\end{array}$ \\
\hline 1. & B.0.7 & 0 & 7 hari & 3 & 3 \\
\hline 2. & B.10.7 & 10 & 7 hari & 3 & 3 \\
\hline 3. & B.20.7 & 20 & 7 hari & 3 & 3 \\
\hline 4. & B.25.7 & 25 & 7 hari & 3 & 3 \\
\hline 5. & B. 30.7 & 30 & 7 hari & 3 & 3 \\
\hline 6. & B.35.7 & 35 & 7 hari & 3 & 3 \\
\hline 7. & B.45.7 & 45 & 7 hari & 3 & 3 \\
\hline 8. & B.55.7 & 55 & 7 hari & 3 & 3 \\
\hline 9. & B. 0.28 & 0 & 28 hari & 3 & 3 \\
\hline 10. & B. 10.28 & 10 & 28 hari & 3 & 3 \\
\hline 11. & B.20.28 & 20 & 28 hari & 3 & 3 \\
\hline 12. & B.25.28 & 25 & 28 hari & 3 & 3 \\
\hline 13. & B.30.28 & 30 & 28 hari & 3 & 3 \\
\hline 14. & B. 35.28 & 35 & 28 hari & 3 & 3 \\
\hline 15. & B. 45.28 & 45 & 28 hari & 3 & 3 \\
\hline 16. & B.55.28 & 55 & 28 hari & 3 & 3 \\
\hline 17. & B. 0.56 & 0 & 56 hari & 3 & 3 \\
\hline 18. & B.10.56 & 10 & 56 hari & 3 & 3 \\
\hline 19. & B.20.56 & 20 & 56 hari & 3 & 3 \\
\hline 20. & B.25.56 & 25 & 56 hari & 3 & 3 \\
\hline 21. & B.30.56 & 30 & 56 hari & 3 & 3 \\
\hline 22. & B. 35.56 & 35 & 56 hari & 3 & 3 \\
\hline 23. & B.45.56 & 45 & 56 hari & 3 & 3 \\
\hline 24. & B.55.56 & 55 & 56 hari & 3 & 3 \\
\hline
\end{tabular}

\section{Setting Alat}

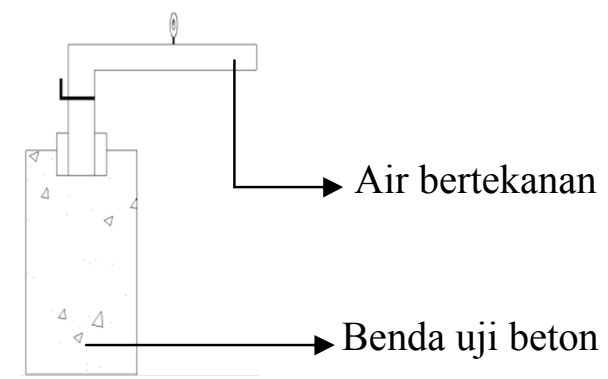

Gambar 1. Pemasangan alat pada benda uji 


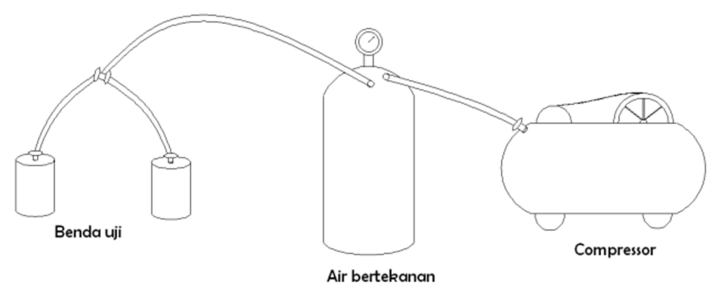

Gambar 2. Setting alat Uji Permeabilitas

Tahapan penelitian secara skematis dapat dilihat pada Gambar 3.

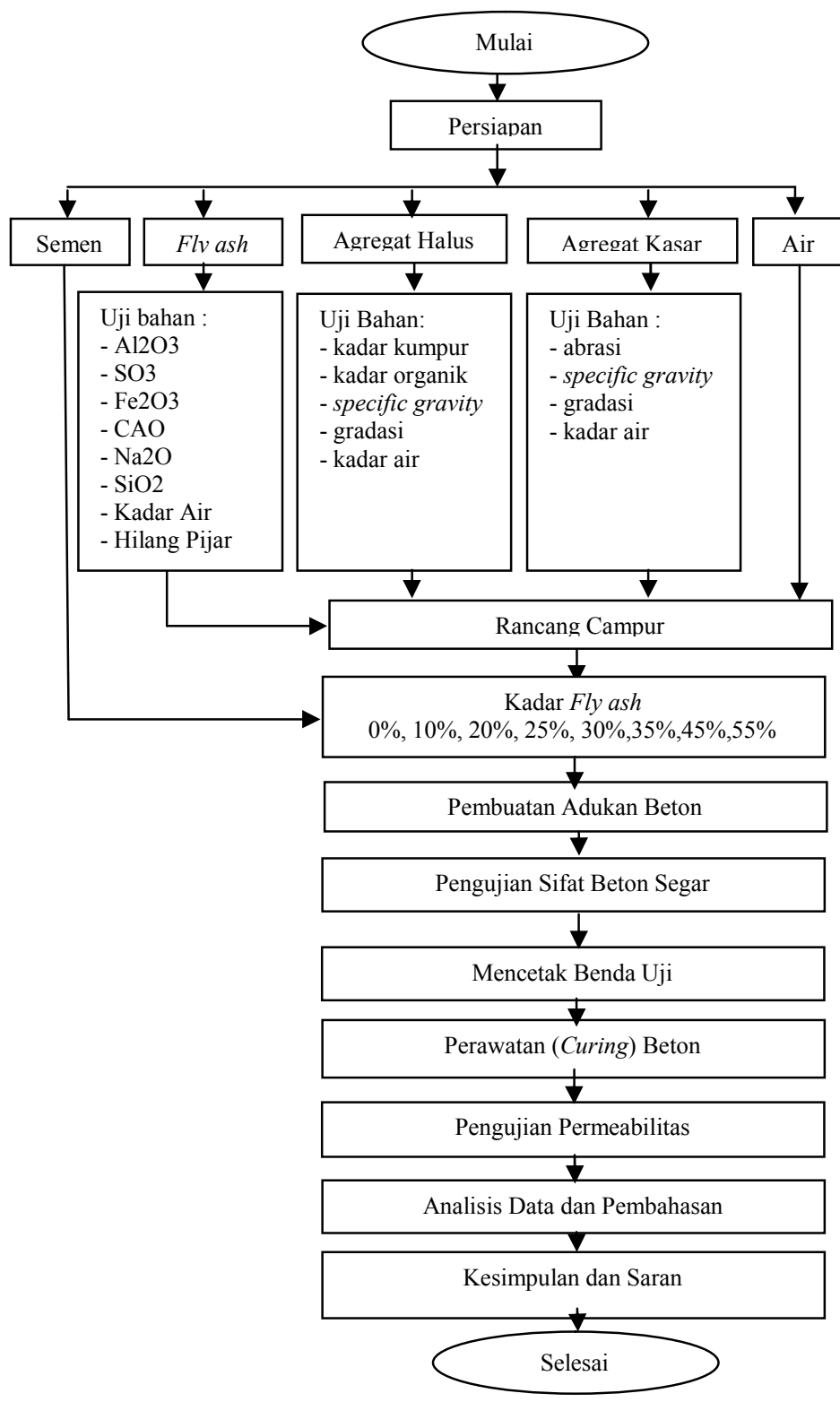

Gambar 3. Bagan alur penelitian

\section{HASIL PENELITIAN DAN PEMBAHASAN}

\section{Rancang Campur Beton}

Tabel 2. Tabel kebutuhan bahan

\begin{tabular}{|c|c|c|c|c|c|c|}
\hline \multirow{2}{*}{ No. } & \multirow{2}{*}{$\begin{array}{c}\text { Kada } \\
\text { r Fly } \\
\text { Ash }\end{array}$} & $\begin{array}{c}\text { Air } \\
\text { (liter) }\end{array}$ & $\begin{array}{c}\text { Semen } \\
(\mathrm{kg})\end{array}$ & $\begin{array}{l}\text { Fly } \\
\text { Ash } \\
\text { (kg) } \\
\end{array}$ & $\begin{array}{c}\text { Agrega } \\
\text { t halus } \\
(\mathrm{kg})\end{array}$ & $\begin{array}{c}\text { Agrega } \\
\mathrm{t} \text { kasar } \\
(\mathrm{kg}) \\
\end{array}$ \\
\hline & & (a) & (b) & (c) & (d) & (e) \\
\hline 1. & $0 \%$ & 3,240 & 7,020 & 0 & 11,160 & 17,460 \\
\hline 2. & $10 \%$ & 3,240 & 6,318 & 0,702 & 11,160 & 17,460 \\
\hline 3. & $20 \%$ & 3,240 & 5,616 & 1,404 & 11,160 & 17,460 \\
\hline 4. & $25 \%$ & 3,240 & 5,265 & 1,755 & 11,160 & 17,460 \\
\hline 5. & $30 \%$ & 3,240 & 4,914 & 2,106 & 11,160 & 17,460 \\
\hline 6. & $35 \%$ & 3,240 & 4,563 & 2,457 & 11,160 & 17,460 \\
\hline 7. & $45 \%$ & 3,240 & 3,861 & 3,159 & 11,160 & 17,460 \\
\hline 8. & $55 \%$ & 3,240 & 3,159 & 3,861 & 11,160 & 17,460 \\
\hline Total & & 25,920 & 40,716 & 15,444 & 89,280 & $\begin{array}{c}139,68 \\
0\end{array}$ \\
\hline
\end{tabular}

Nilai Slump

Tabel 3. Data hasil pengujian nilai slump

\begin{tabular}{|c|c|}
\hline Kadar Fly ash & Slump Loss (mm) \\
\hline $0 \%$ & 115 \\
\hline $10 \%$ & 120 \\
\hline $20 \%$ & 123 \\
\hline $25 \%$ & 125 \\
\hline $30 \%$ & 128 \\
\hline $35 \%$ & 131 \\
\hline $45 \%$ & 136 \\
\hline $55 \%$ & 147 \\
\hline
\end{tabular}

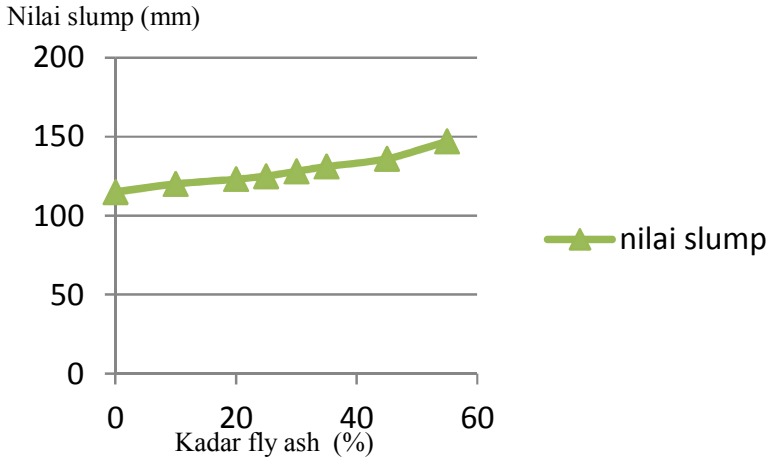

Gambar 4. Grafik pengujian nilai slump

Workability merupakan faktor yang penting dalam pembuatan adukan beton. Workability yang memadai sangat diperlukan untuk memudahkan proses pengadukan, pengangkutan, penuangan, dan pemadatan. Berdasarkan pengujian nilai slump tampak bahwa penggunaan fly ash pada 
rancang campur (mix design) akan mempengaruhi workability.

\section{Kuat Tekan}

Tabel 4. Data hasil pengujian kuat tekan

\begin{tabular}{|c|r|r|r|}
\hline $\begin{array}{c}\text { Kadar } \boldsymbol{F l y} \\
\boldsymbol{a s} \boldsymbol{h}\end{array}$ & $\begin{array}{c}\text { Kuat tekan } \\
\text { rata-rata } \\
\text { (7 hari) }\end{array}$ & $\begin{array}{c}\text { Kuat tekan } \\
\text { rata-rata } \\
\text { (28 hari) }\end{array}$ & $\begin{array}{c}\text { Kuat tekan } \\
\text { rata-rata } \\
\text { (56 hari) }\end{array}$ \\
\hline $0 \%$ & 18,101 & 24,889 & 30,545 \\
\hline $10 \%$ & 16,970 & 25,455 & 31,677 \\
\hline $20 \%$ & 13,576 & 26,020 & 32,808 \\
\hline $25 \%$ & 12,444 & 26,774 & 33,939 \\
\hline $30 \%$ & 11,313 & 28,660 & 37,333 \\
\hline $35 \%$ & 9,051 & 30,168 & 38,465 \\
\hline $45 \%$ & 6,788 & 32,431 & 40,727 \\
\hline $55 \%$ & 5,657 & 16,970 & 22,626 \\
\hline
\end{tabular}

Kuat tekan (MPa)

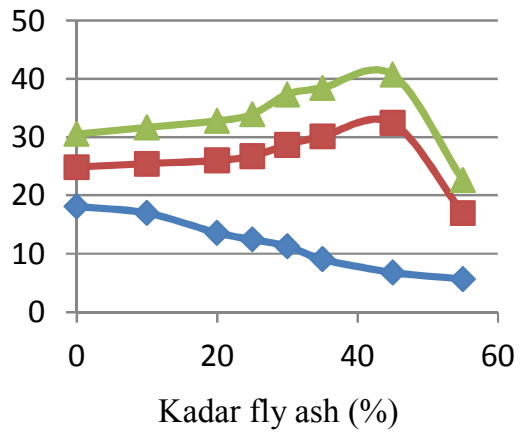

$\sim$ kuat tekan hari

-kuat tekan hari

- kuat tekan hari

Gambar 5. Grafik pengujian kuat tekan

Berdasarkan hasil pengujian kuat tekan pada saat umur 7 hari, penggantian fly ash terhadap semen menurunkan kuat tekan beton. Pada pengujian kuat tekan umur 28 hari dan 56 hari, diperoleh peningkatan kuat tekan beton pada variasi $10 \%$, $20 \%, 25 \%, 30 \%, 35 \%$ dan $45 \%$ dari penggantian fly ash terhadap semen. Pada variasi $55 \%$ terjadi penurunan kuat tekan beton. Berarti tercapai optimasi penggantian fly ash terhadap semen pada variasi $45 \%$ fly ash terhadap berat semen.

\section{Permeabilitas}

Tabel 5. Data hasil permeabilitas

\begin{tabular}{|c|c|c|c|}
\hline $\begin{array}{c}\text { Kadar Fly } \\
\text { ash }\end{array}$ & $\begin{array}{c}\text { Permeabilitas } \\
\text { (7 hari) }\end{array}$ & $\begin{array}{c}\text { Permeabilitas } \\
\text { (28 hari) }\end{array}$ & \multicolumn{1}{c|}{$\begin{array}{c}\text { Permeabilitas } \\
\text { (56 hari) }\end{array}$} \\
\hline $0 \%$ & $7,309 \mathrm{E}-09$ & $6,944 \mathrm{E}-09$ & $6,597 \mathrm{E}-09$ \\
\hline $10 \%$ & $6,608 \mathrm{E}-09$ & $6,278 \mathrm{E}-09$ & $5,964 \mathrm{E}-09$ \\
\hline $20 \%$ & $6,029 \mathrm{E}-09$ & $5,728 \mathrm{E}-09$ & $5,441 \mathrm{E}-09$ \\
\hline
\end{tabular}

\begin{tabular}{|l|r|r|r|}
\hline $25 \%$ & $5,381 \mathrm{E}-09$ & $5,112 \mathrm{E}-09$ & $4,856 \mathrm{E}-09$ \\
\hline $30 \%$ & $4,816 \mathrm{E}-09$ & $4,576 \mathrm{E}-09$ & $4,347 \mathrm{E}-09$ \\
\hline $35 \%$ & $4,419 \mathrm{E}-09$ & $4,198 \mathrm{E}-09$ & $3,988 \mathrm{E}-09$ \\
\hline $45 \%$ & $3,867 \mathrm{E}-09$ & $3,673 \mathrm{E}-09$ & $3,490 \mathrm{E}-09$ \\
\hline $55 \%$ & $3,450 \mathrm{E}-09$ & $3,277 \mathrm{E}-09$ & $3,113 \mathrm{E}-09$ \\
\hline
\end{tabular}

Koef.permeabilitas(m/dt)

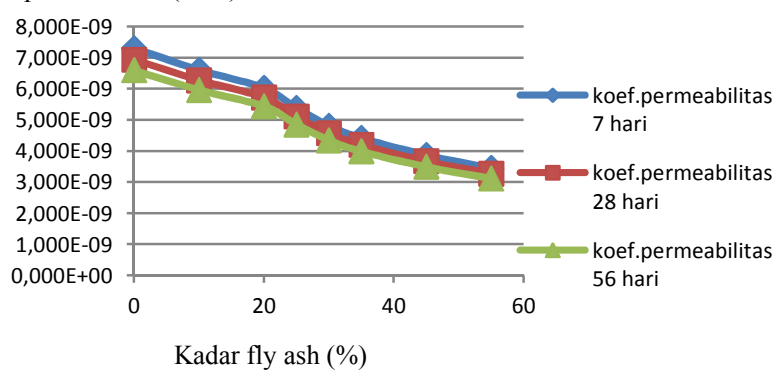

Gambar 6. Grafik pengujian permeabilitas

Berdasarkan hasil pengujian permeabilitas beton dengan variasi kadar penggantian semen yang disajikan pada Tabel 5 diketahui bahwa nilai koefisien permeabilitas beton yang paling rendah terjadi pada kadar fly ash sebesar $55 \%$ dengan nilai koefisien permeabilitas pada 7 hari $3,45010^{-9}$ $\mathrm{m} / \mathrm{dt}$, pada 28 hari $3,27710^{-9} \mathrm{~m} / \mathrm{dt}$ dan pada 56 hari $3,11310^{-9} \mathrm{~m} / \mathrm{dt}$. Semakin rendah nilai koefisien permeabilitas beton menunjukkan bahwa beton tersebut semakin impermeable sehingga sulit dilewati oleh gas atau cairan. Beton yang padat dan sulit dilewati oleh gas maupun cairan membuat durabilitas beton semakin baik.

\section{KESIMPULAN}

Dari hasil pengujian, analisis data dan pembahasan maka dapat ditarik beberapa kesimpulan sebagai berikut:

1. Penggunaan fly ash dengan kadar tertentu dapat mempengaruhi sifat beton segar yang dihasilkan, semakin tinggi kandungan fly ash yang digunakan semakin baik pula workability beton segar yang dihasilkan.

2. Penggunaan material fly ash dapat menurunkan biaya produksi untuk beton normal yang memiliki sifat self healing concrete (SHC) dan beton ramah lingkungan green concrete karena dapat mereduksi sebagian atau lebih kebutuhan penggunaan semen pada campuran beton.

3. Salah satu faktor utama yang mempengaruhi nilai kuat tekan beton adalah umur beton. 
Penggunaan kadar fly ash diatas 50\% dari berat binder yang digunakan memiliki nilai kuat tekan awal yang kurang baik untuk pengerjaan beton yang memerlukan waktu pengerasan dan kekuatan awal yang tinggi, karena proses pengerasan (setting time) dan penambahan kekuatan betonnya agak lambat pada umur beton kurang dari 28 hari. Setelah umur 28 hari kuat tekan beton yang menggunakan fly ash sebagai penggantian sebagian semen mengalami kenaikan rata-rata sebesar $27 \%$ pada kadar $10 \%, 20 \%, 25 \%$, $30 \%, 35 \%$ dan $45 \%$ dibanding dengan beton normal. Tetapi pada kadar 55\% kuat tekan beton menurun. Kuat tekan optimum terjadi pada kadar $45 \%$.

4. Penggunaan fly ash sebagai pengganti semen dapat memperkecil nilai koefisien permeabilitas beton. Semakin rendah nilai koefisien permeabilitas beton menunjukkan bahwa beton tersebut semakin impermeable sehingga sulit dilewati oleh gas atau cairan. Beton yang padat dan sulit dilewati oleh gas maupun cairan membuat durabilitas beton semakin baik.

\section{DAFTAR PUSTAKA}

Anonim. 1918. American Society For Testing and Material (ASTM). Philadelpia.

Anonim. 1992. Annual Book of ACI Standart. American Concrete Institute. Detroit Michigan.

Anonim. 2009. Setting and Hardening of Geopolymeric Cement Pastes Incorporated with Fly Ash. American Concrete Institute. Detroit Michigan.

Anonim. 1982. Peraturan Umum Bahan Bangunan Indonesia (PUBI). Jakarta.

Hardjito. 2001. Abu Terbang Solusi Pencemaran Semen. Sinar Harapan. Kupang.

Kurniawandy, Alex., Djauhari, Zulfikar., Napitu, Elpin Tua. 2011. Pengaruh Abu Terbang terhadap Karakteristik Mekanik Beton Mutu Tinggi. Pekanbaru.

Limantra, S dan Sugiarto, H. 2010. Penelitian Awal Pada High Volume Fly Ash Concrete. Surabaya.

Malhotra, V.M. \& Mehta, P.K. 2003. High Performance, High-Volume Fly Ash Concrete: Materials, Mixture Proportioning, Properties, Construction Practice, and Case Histories. Ottawa, Canada: Supplementary Cementing Materials for Sustainmable Developments Inc.

Maryoto, A. 2008. Pengaruh Penggunaan High Volume Fly Ash pada Kuat Tekan Mortar. Purwokerto.

McCormac, J.C. 2003. Desain Beton Bertulang. Erlangga. Jakarta.

Mehta, P. Kumar, Monteiro, P. Concrete : 2004. The McGraw Hill Companies.

Mehta, P. Kumar. 2006. High Performance, high volume fly ash concrete for sustainable development. University of California. Berkeley, USA.

Mehta, P. Kumar. 2005. Recent Applications of HVFA Concrete in North America. Berkeley, USA.

Mulyono, T. 2005. Teknologi Beton. Andi. Yogyakarta.

Murdock, L.J \& Brook, K.M, (alih bahasa: Stephanus Hendarko). 1991. Bahan dan Praktek Beton. Erlangga. Jakarta.

Nawy, E.G.1990. Beton Bertulang Suatu Pendekatan Dasar. Eresco. Bandung.

Nugraha, P \& Antoni. 2007. Teknologi Beton. Andi. Yogyakarta.

Obla, Karthik H. 2008. Specifying Fly Ash fo Use in Concrete. NRMCA.

Stefanus, L. \& Howard, S. 2010. Penelitian Awal pada High Volume Fly Ash Concrete. Surabaya.

Tjokrodimuljo, K. 1996. Teknologi Beton. Arif. Yogyakarta. 